\title{
تأثير اسلويب الاكتشاف الموجه والتعليم المبرمج في تعلم وتطور الشكل الحركي الكينماتيكي لمهارة
}

\section{الضرب الساحق في الكرة الطائرة}

أ.د.د. علاء محسن ياسر

كلية التربية البذنية وعلوم الرياضية - جامعة بغداد

alaamohsun@gmail.com

(00964) 07707992708
حسن هادي حسين

كلية التربية البدنية وعلوم الرياضية - جامعة بغداد

hassan.hassan44aa@gmail.com

(00964) 07821541129

مستخلص البحث باللغة العربية

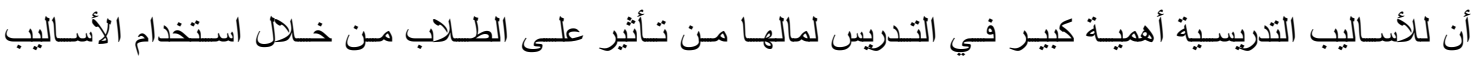

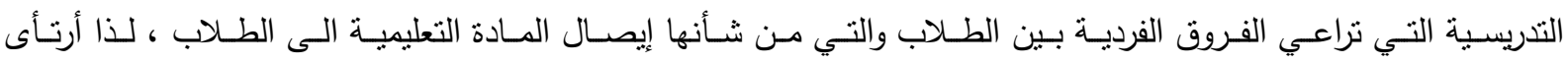

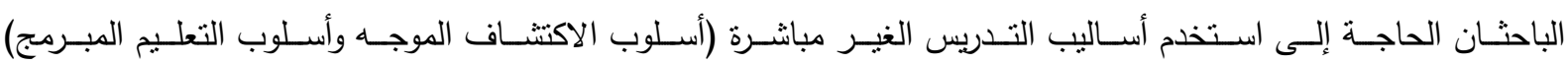

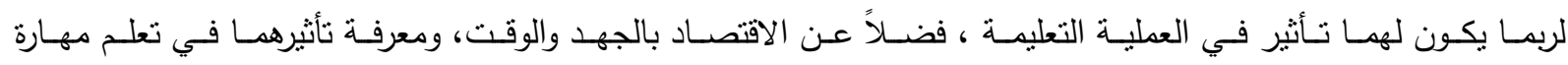

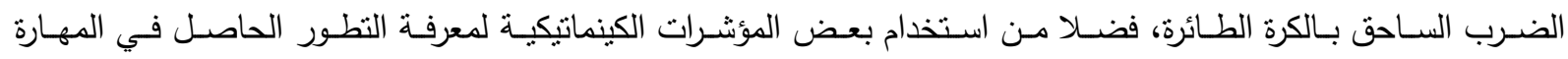

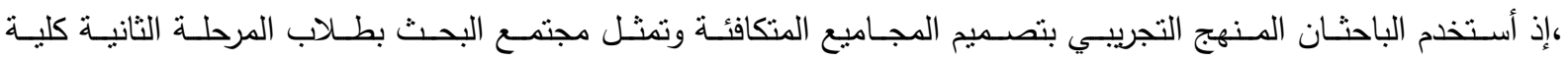

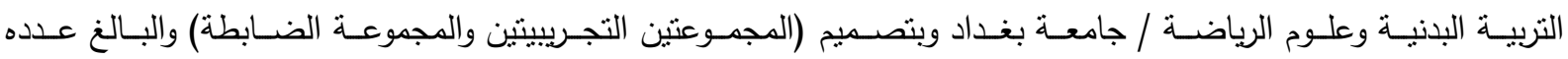

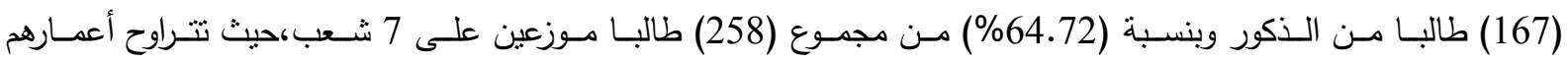

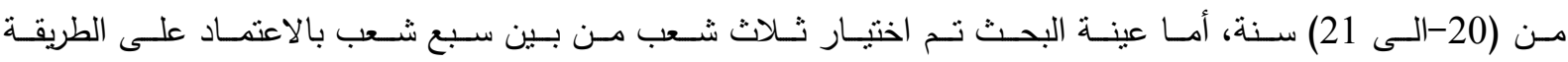

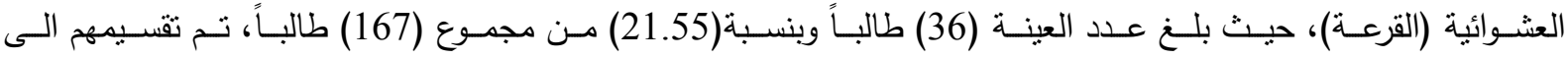

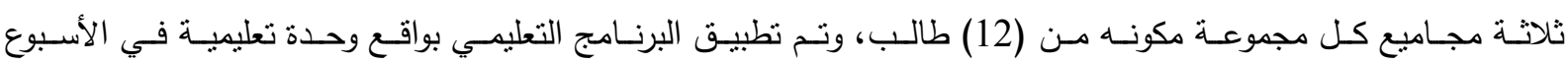

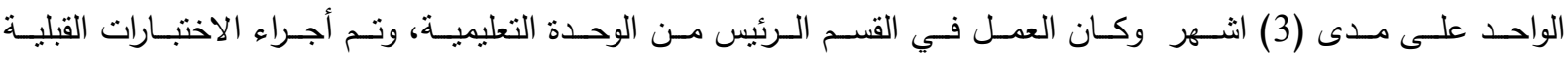

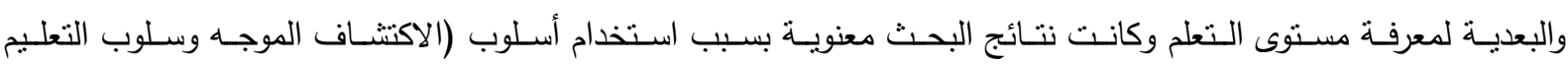

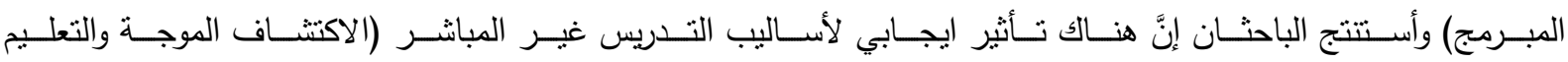

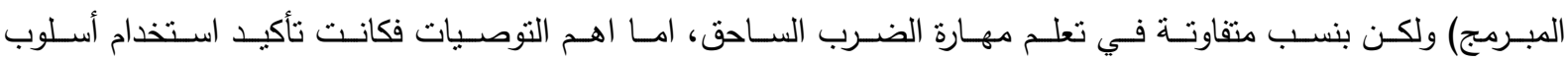
الاكتثاف الموجه في تعلم مهارة الضرب الساحق بالكرة الطائرة.

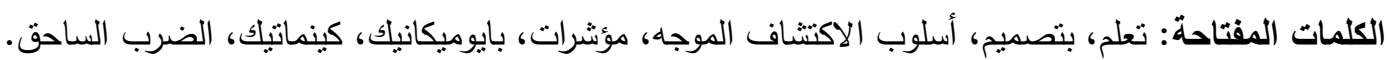

\section{ABSTRACT}

\section{The Effect of Guided Discovery And Programed Teaching On Learning} and Developing Kinematic Motor Form Of Spike In Volleyball

\section{Hassan Hadi Hussein}

College of Physical Education and Sports

Sciences - University of Baghdad
Asst. prof. Dr. Alla Mohsen Yaser

College of Physical Education and Sports

Sciences - University of Baghdad

Teaching styles play an important role in teaching due to their great effect on students thus the researchers used indirect teaching styles (guided discovery and programed teaching for their effective results. The research aimed at identifying the effect of these styles on learning spike in volleyball. The researchers used the experimental method on (167) male second year students from physical education and sport science college / University of Baghdad aged 20 21. Three sections were selected and divided into three groups each group consisted of (12) student. The program was applied with one teaching session per week for 3 months. The results showed that there is a positive effect in using guided discovery and programed teaching in spiking. Finally the researchers recommended using these styles in learning spiking in volleyball.

Keywords: learning, designing, guided discovery, indicators, biomechanics, kinematics, spike. 


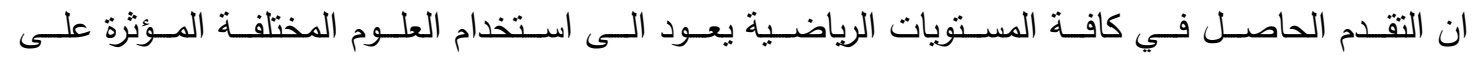

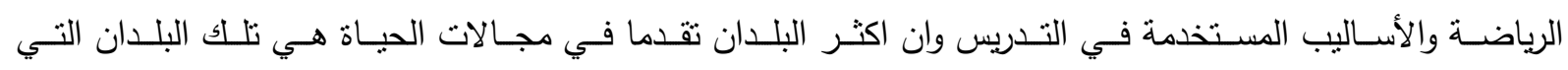

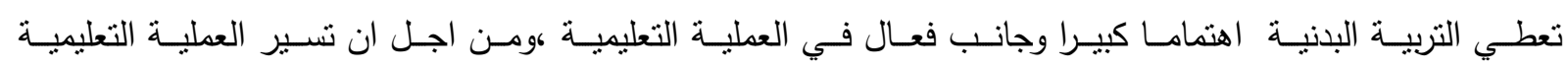

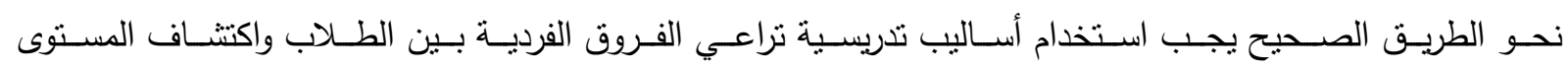

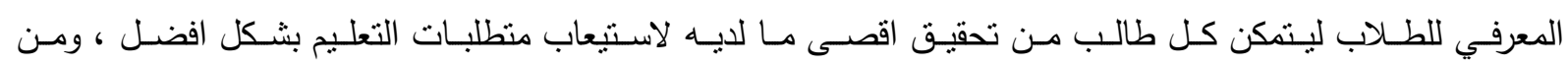

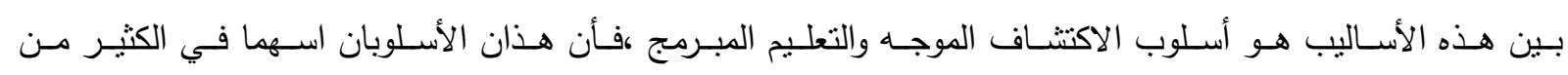

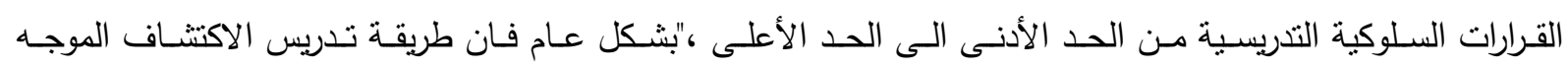

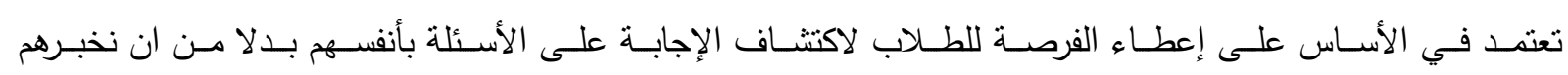

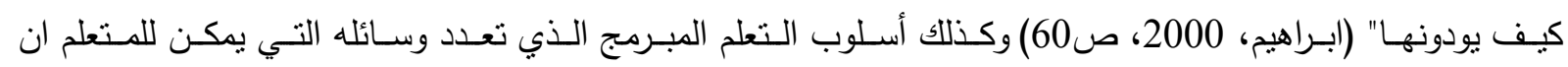

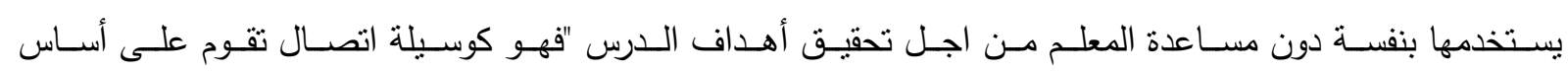

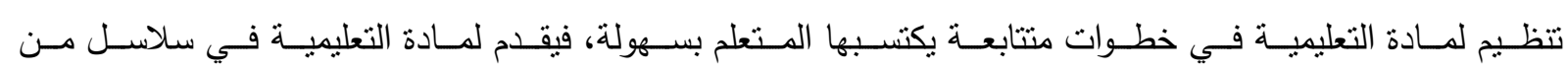

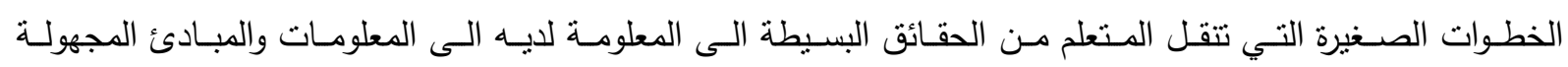

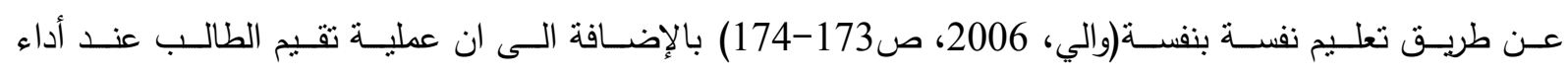

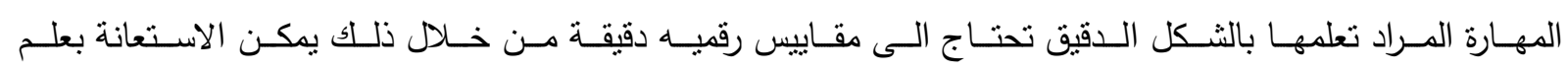

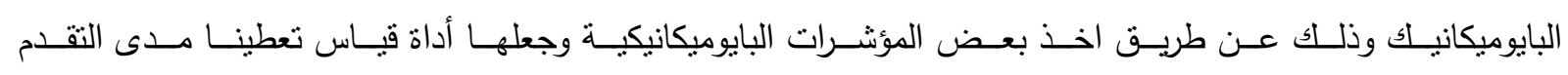

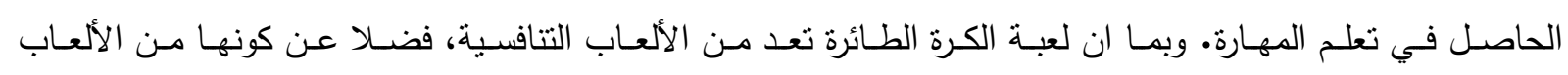

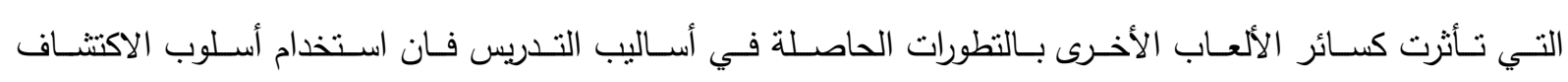
الموجه والتعلم المبرمج ربما سيكون له دور كبير في تعليم المهارات الأساسية والفنية بالكرة الطائرة.

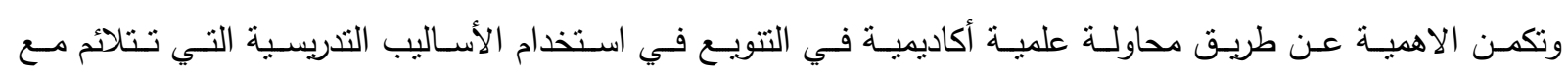

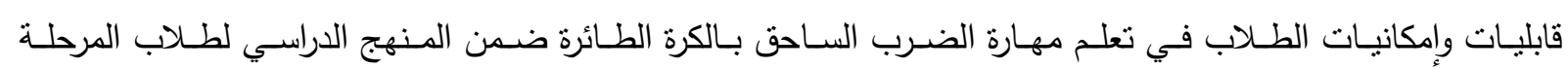

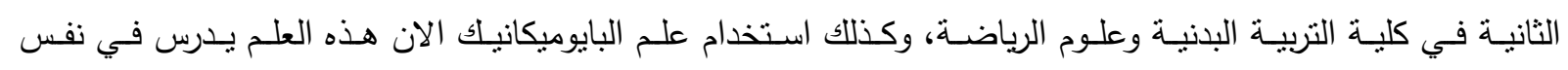

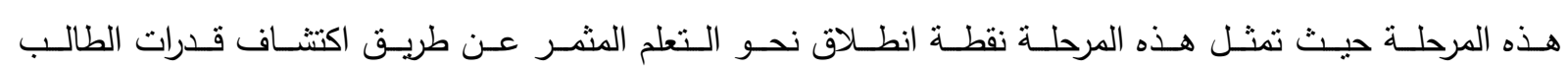

وإمكانياته وتوجيهها بالثكل الصحيح.

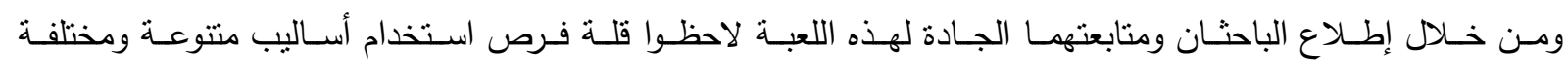

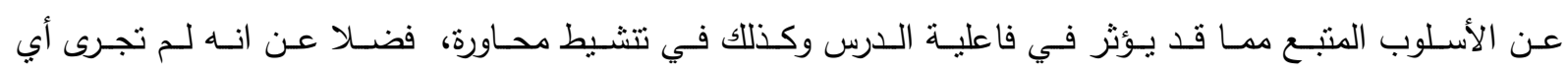

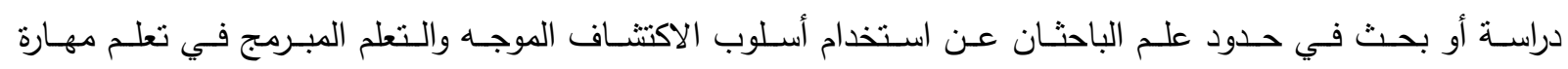

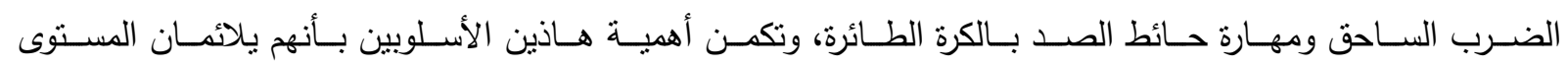

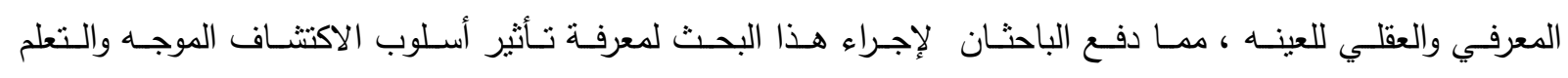

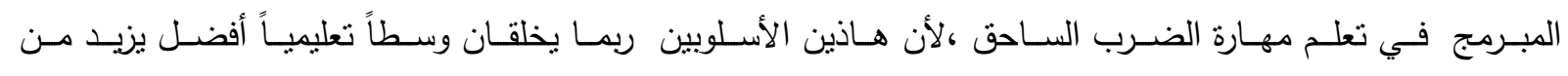

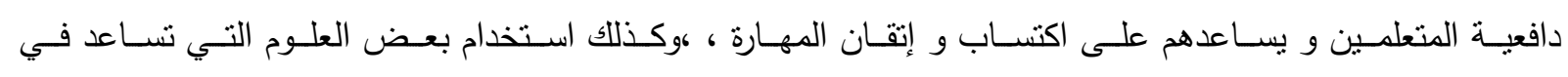

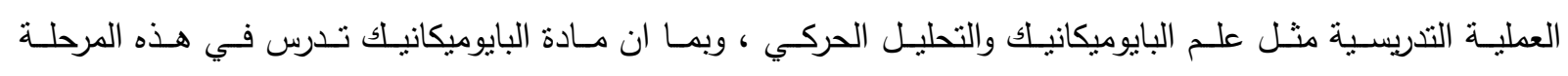

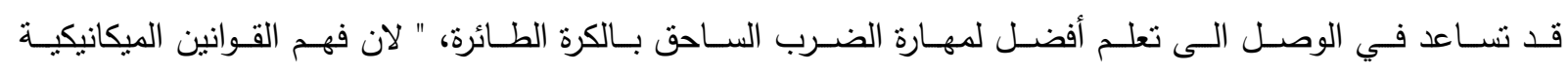

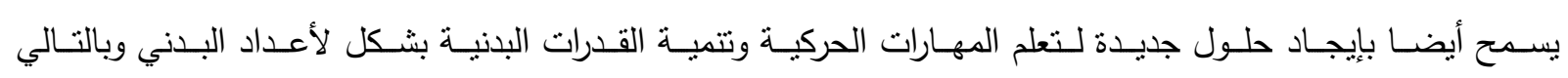

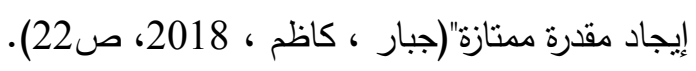




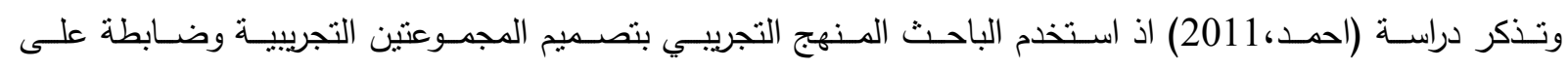

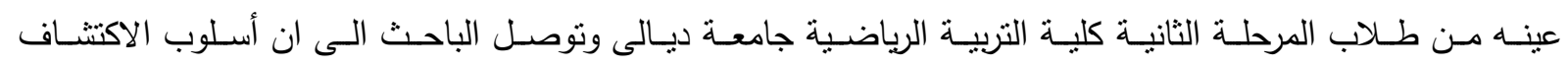
الموجه له تأثثر إيجابي في تعلم واكتساب مهارة الارسال بالتتس الأرضي.

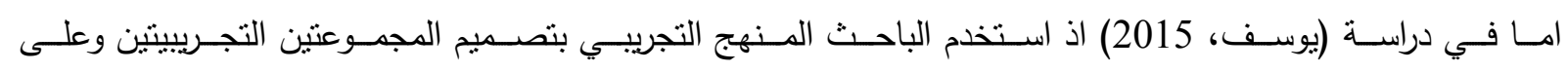

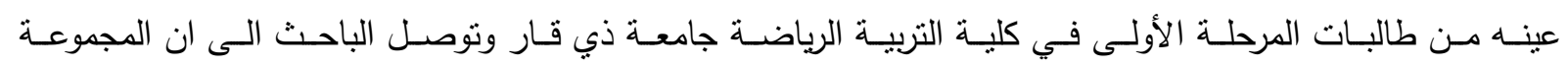

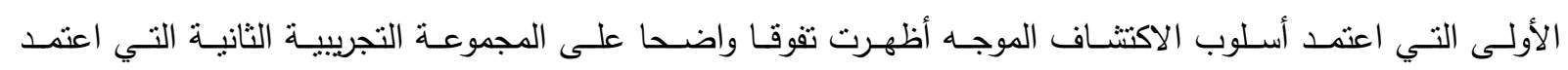
أسلوب التعلم بالأهداف في الاختبارات البعدية لبعض المهارات الأساسية بكرة السلة.

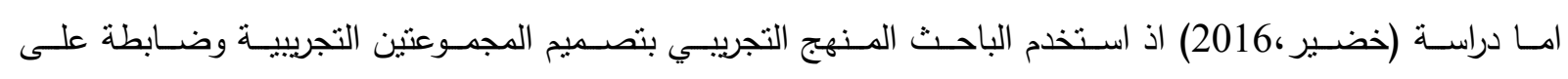

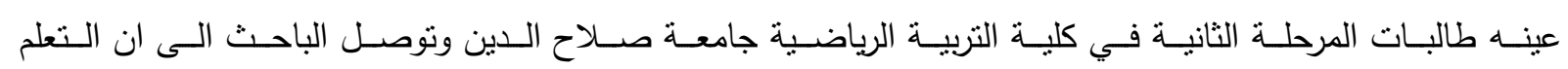

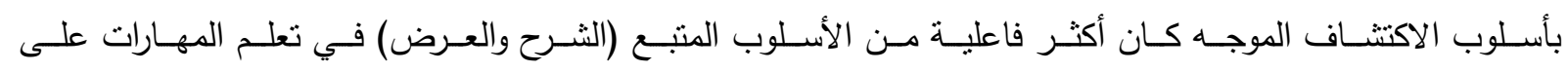
جهازي عارضة التوازن ومنوازي مختلف الارتفاعات.

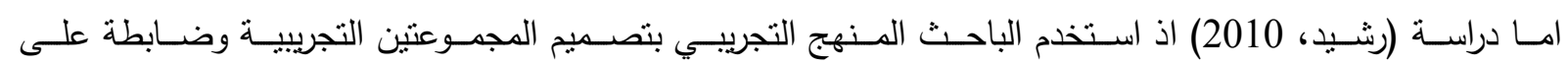

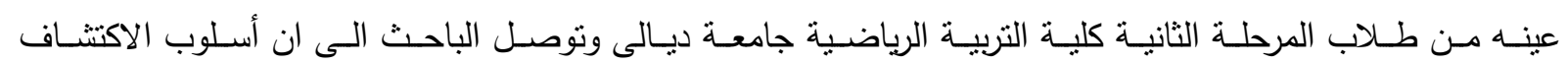
الموجه كان مؤثرا في مستوى أداء اللعب لمهارة استقبال الارسال بالكرة الطائرة.

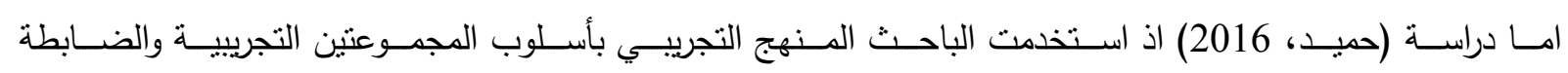

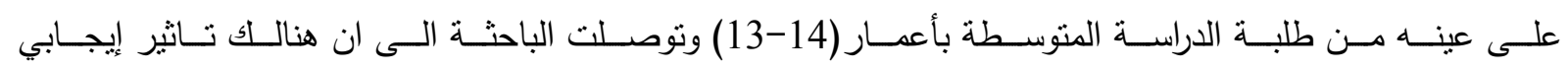

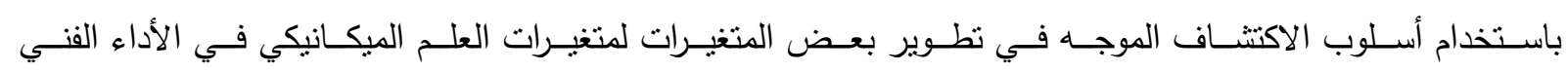
لفعالية رمي الرمح.

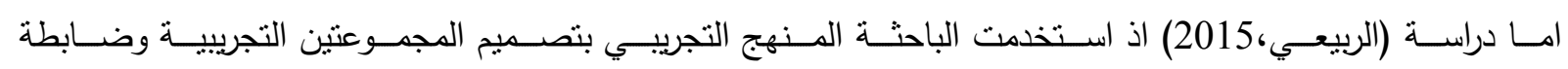

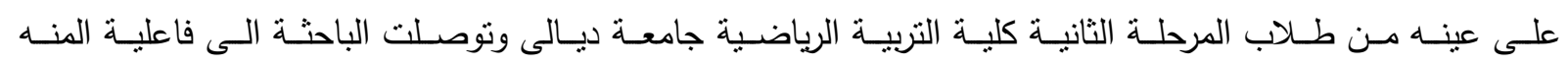

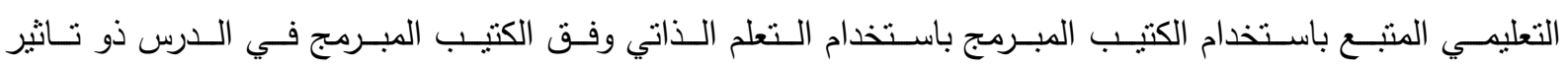
إيجابي في تطوير تركيز الانتباه والتصور العقلي وتعلم مهارتي المناولة والتصويب بكرة السلة.

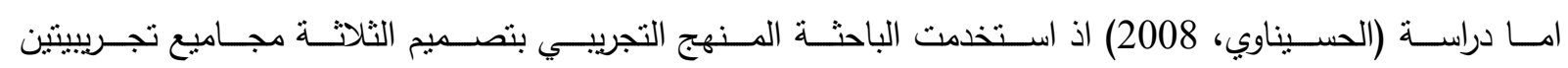

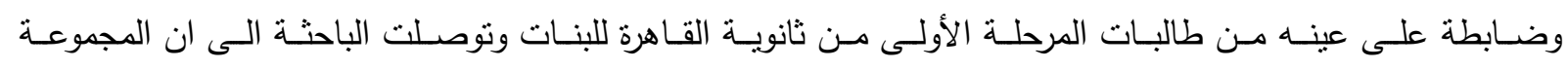

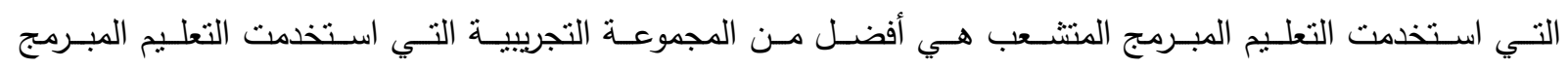
بالنظام الخطي وكذألك المجموعة الضابطة في تعلم مهارتي المحاورة والتمريرة الصدرية بكرة السلة.

\section{الطريقة والأدوات:}

تم استخدم المنهج التجريبي بأسلوب المجموعتين التجريبيتين والمجموعة الضابطة، تكون مجتمع البحث من طلاب المرحلة الثانية في كلية التربية البدنية وعلوم الرياضة جامعة بغداد للعام الدراسي (2018-2019) م والبالغ عدده الندان

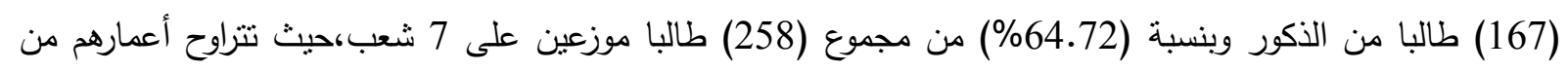
(20-الى 21) سنة، أما عينة البحث نم اختيار ثلاثة شعب من بين سبعة شعب بالاعتماد على الطريقة العشوائية

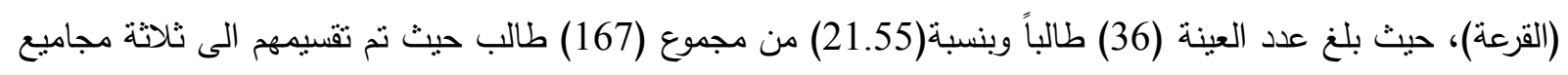

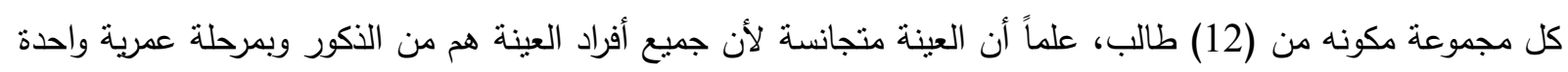

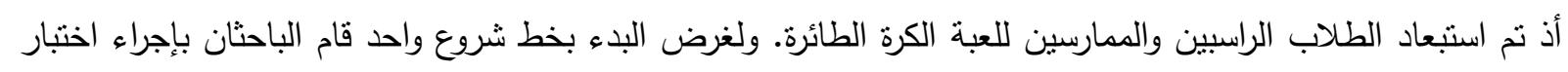
التكافؤ لمجاميع البحث باستخدام اختبار (F) عبر الاختبار القبلي لمهارة الضرب الساحق، والجدول (1) يبين ذلك. 
مجلة كلية التربية الرياضية / جامعة بغداد * المجلد الحادي والثلاثون * العدد الثالث * 2019.

جدول (1) تكافؤ مجاميع البحث للمنغيرات الكينماتيكية في مهارة الضرب الساحق

\begin{tabular}{|c|c|c|c|c|c|c|c|c|c|}
\hline \multirow{2}{*}{ الفروق } & \multirow{2}{*}{ Sig } & \multirow{2}{*}{ قالمحسوية } & \multicolumn{2}{|c|}{ المجموعة الثالثة } & \multicolumn{2}{|c|}{ المجموعة الثانية } & \multicolumn{2}{|c|}{ المجموعة الأولى } & /المجموعة \\
\hline & & & $\varepsilon$ & س & $\varepsilon$ & س & $\varepsilon$ & س & \\
\hline عشوائي & 0.646 & 0.442 & 3.725 & 46.666 & 3.737 & 47.833 & 3.449 & 47.916 & زاوية الانطلاق \\
\hline عشوائي & 0.953 & 0.048 & $\mathbf{3 . 3 3 3}$ & 124.250 & 3.203 & 124.416 & 3.357 & 124.000 & للصى انثاء \\
\hline عشوائي & 0.922 & 0.082 & 0.120 & 3.743 & 0.132 & 3.754 & 0.131 & 3.764 & سرعة الانطلاق \\
\hline عشوائي & 0.798 & 0.227 & 0.094 & 2.797 & 0.109 & 2.790 & 0.105 & 2.817 & لحظة الضرب الكرة \\
\hline
\end{tabular}

اختبار تقويم الأداء القني لمهارة الضرب الساحق (صدام محمد فريد، 2006، ص66).

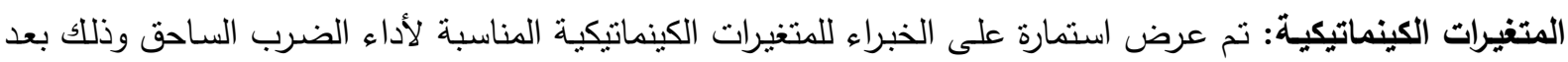
تصوير الاختبارات القبلية. زاوية الانطلاق /(قصى انثناء للركبة//ارتفاع الكرة لحظة الضرب / سرعة الانطلاق: وتقاس من نقطة مفصل الورك عند اخر مس للأرض خلال المسافة التي يقطها الجسم بزمن (0.083) ثا، وحدة قياسها (م/ثا) وتقسم المسافة على الزئه الزمن.

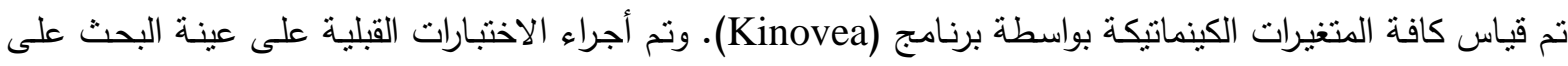

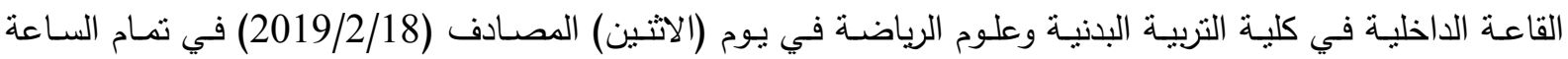

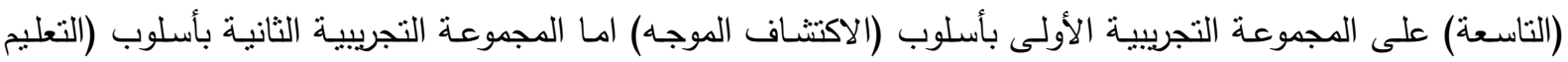

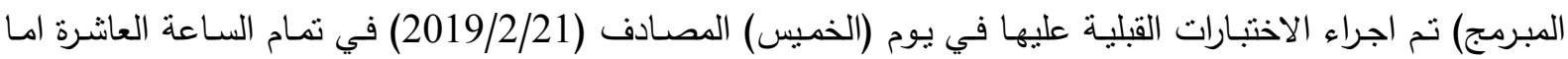
المجموع (الضـابطة) فقد تم اجراء الاختبارات القبلية عليها في يوم (الاحد) المصادف (2019/2/24) في تمام الساعة

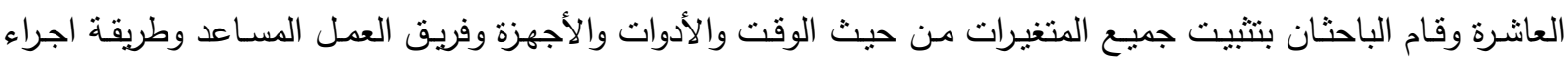
الاختبارات، من اجل تحقيق الظروف نفسها بالكرة الطائرة، وتتفيذها عند اجراء الاختبارات البعدية.

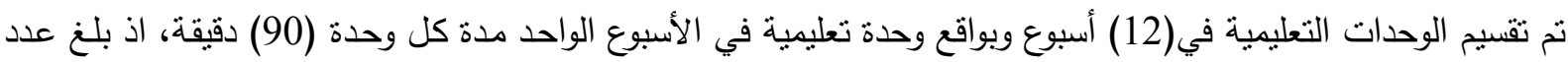
الوحدات التعليمية لكل مجموعة (12) وحدة تعليمية لكل أسلوب، أسلوب الاكتشاف الموجه و (12) وحدة، وكذلك أسلوب التعليم المبرمج (12) وحدة. ويتم تطبيق هذه الاساليب في القسم الرئيسي فقط ومدته (65 دقيقة) ويتضمن الجانب التعليمي ومدته (10 دقيقة) يتم فيها شرح المهارة للطلاب ويتم طرح الأسئلة في أسلوب الاكتشاف الموجه وأسلوب التعلم المبرمج امـا الجانب النطبيقي ومدته (55 دقيقة) وفي هذا القسم من الدرس يبدأ الطلاب بتطبيق اداء المهارة على وفق إجاباتهم على الأسئلة للأسلوب ويشارك

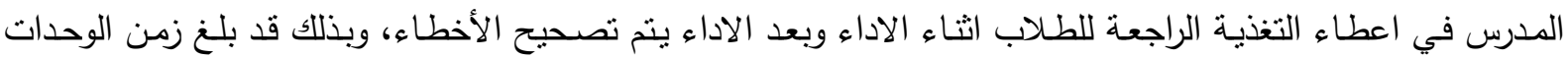
التعليمية (1080) دقيقة لكل أسلوب. و قبل البدء بتطبيق التجربة الرئيسية قام الباحثان بأجراء وحدة تعريفية للطلاب بالكرة الطائرة وكذللك افراد فريق العمل المساعد لتوضيح طريقة تطبيق البرنامج التعليمي لتعليم مهارة الضرب الساحق بأسلوب الاكتثاف الموجه والتعليم المبرمج،

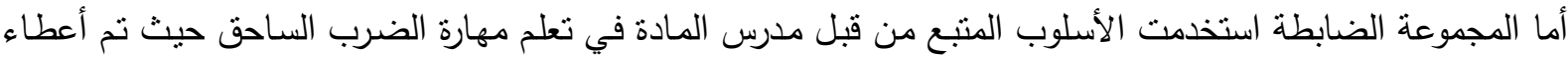
لمجاميع البحث المادة التعليمية المراد تعلمها. قام الباحثان بأعداد مجموعة من الأسئلة بأسلوب الاكتشاف الموجه في كل مهارة تتضمن هذه الأسئلة سؤالا عن مهارة

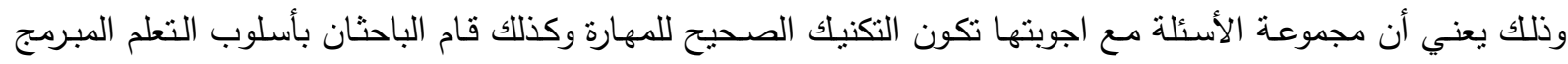

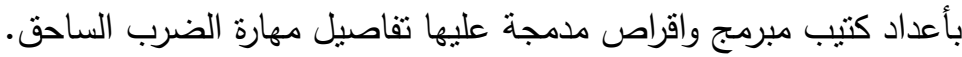


تعلمت المجموعة التجريبية الاولى بأسلوب الاكتشاف الموجه وتم تتفيذه في القسم الرئيسي ، إذ يبدأ المدرس بشرح المهارة

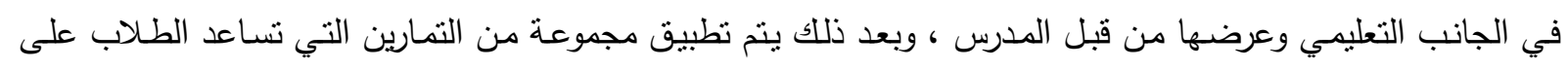

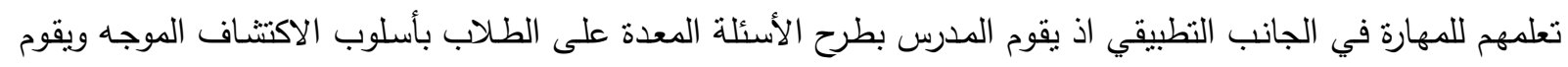

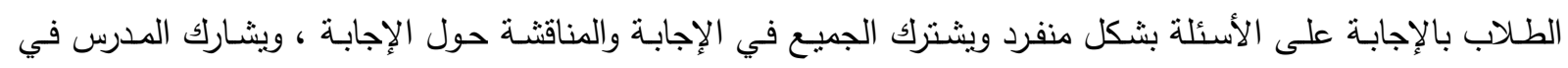

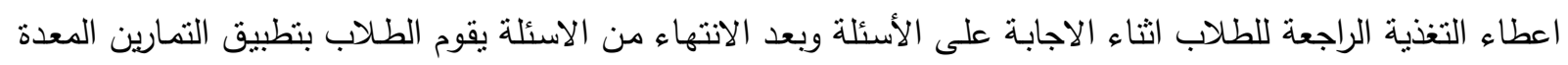

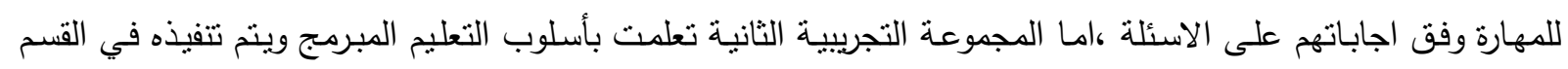

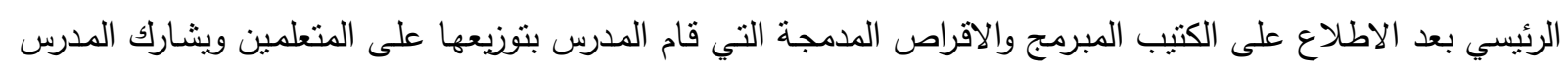
في إعطاء التغذية الراجعة. المجموعـة الضـابطة (الطريقة المتبعـة): تعلمت هذه المجموعـة بالطريقة المتبعة من قبل مدرس (الأسلوب الامري) في

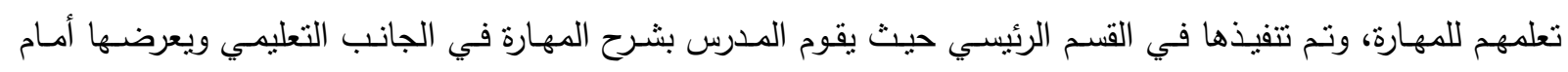

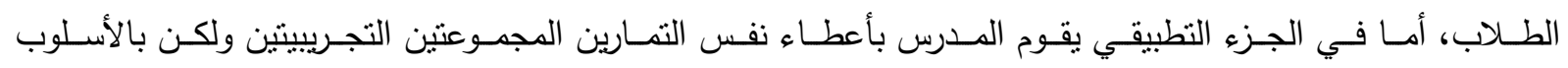
المتبع(الامري) التي تساعد الطلاب على نعلم المهارة.

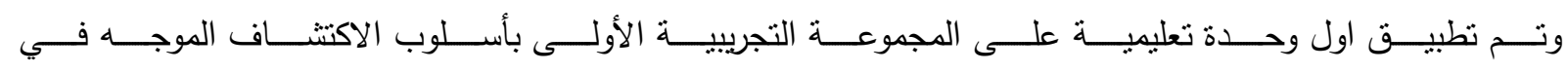

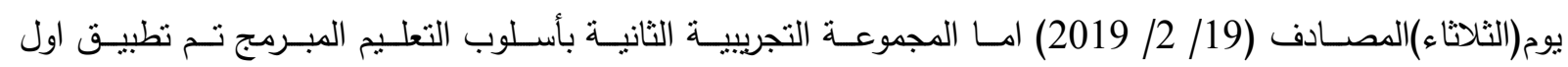

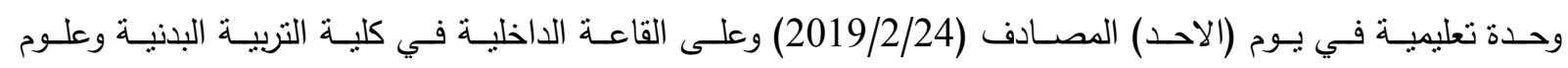

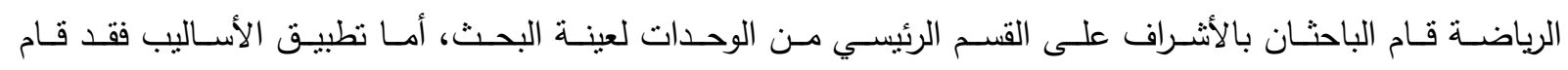

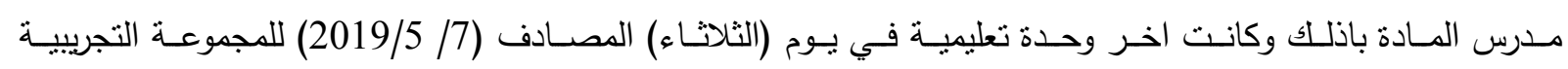

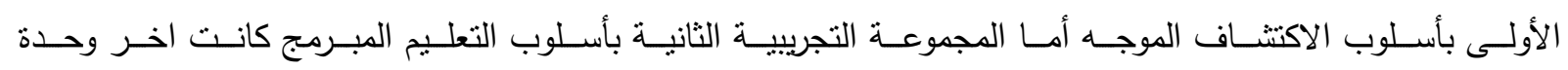
تعليمية في يوم (الاحد) المصادف (2019/5/12). تم أجراء الاختبـارات البعديـة لعينـة البحث في يـوم (الاربعـاء) المصـادف (5/8/ 2019) وفي تمـام السـاعة (التاسـعة)

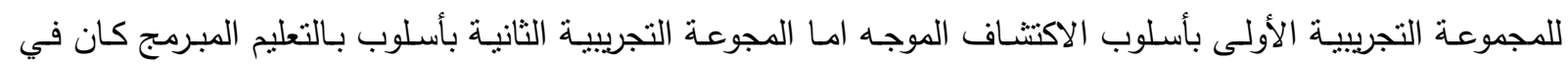

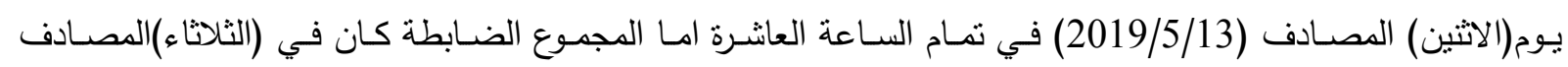

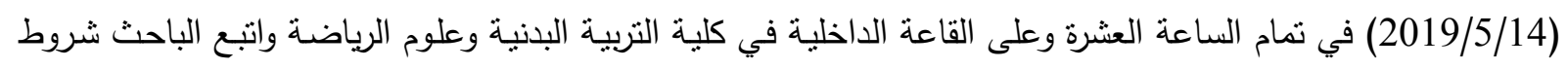

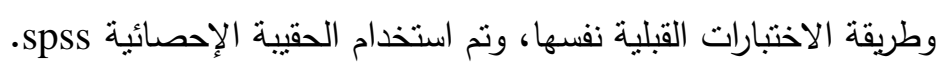

النتائج:

جدول (2) بين الوسط الحسابي والانحراف المعياري وقيمة (t) للاختبار القبلي والبعدي للجموعة الاكتشاف الموجة

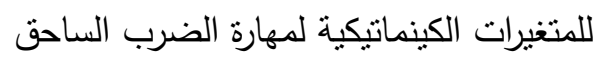

\begin{tabular}{|c|c|c|c|c|c|c|c|}
\hline \multirow{2}{*}{ مستوى الدلالة } & \multirow{2}{*}{ *Sig } & \multirow{2}{*}{ المحسوبة } & \multicolumn{2}{|c|}{ الاختبار البعدي } & \multicolumn{2}{|c|}{ الاختبار القبلي } & \multirow{2}{*}{ المتغيرات } \\
\hline & & & $\varepsilon$ & س & $\varepsilon$ & س - س & \\
\hline معنوي & 0.000 & 14.451 & 4.589 & 65.833 & 3.449 & 47.916 & زاوية الانطلاق \\
\hline معنوي & 0.000 & 9.830 & 4.864 & 104.750 & 3.357 & 124.000 & اقصى انثاء للركبة \\
\hline معنوي & 0.000 & 9.618 & 0.373 & 4.854 & 0.131 & 3.764 & سرعة الانطلاق \\
\hline معنوي & 0.000 & 9.099 & 0.106 & 2.975 & 0.105 & 2.817 & ارتفاع الكرة لحظة الضرب \\
\hline
\end{tabular}

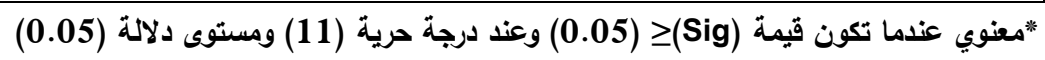


جدول (3) بين الوسط الحسابي والانحراف المعياري وقيمة (t) للاختبار القبلي والبعدي لمجموعة التعليم المبرمج للمتغيرات الكينماتيكية لدهارة الضرب الساحق

\begin{tabular}{|c|c|c|c|c|c|c|c|}
\hline \multirow{2}{*}{ مستوى } & \multirow{2}{*}{ Sig } & \multirow{2}{*}{ قلميم T المسوبة } & \multicolumn{2}{|c|}{ الاختبار البعدي } & \multicolumn{2}{|c|}{ الاختبار القبلي } & \multirow{2}{*}{ المتغيرات } \\
\hline & & & $\varepsilon$ & س & $\varepsilon$ & س & \\
\hline معنوي & 0.001 & 4.650 & 4.737 & 53.083 & 3.737 & 47.833 & زاوية الانطلاق \\
\hline معنوي & 0.002 & 4.056 & 4.141 & 118.333 & 3.203 & 124.416 & اقصى انثاء للركبة \\
\hline معنوي & 0.037 & 2.369 & 0.209 & 3.910 & 0.123 & 3.754 & سرعة الانطلاق \\
\hline معنوي & 0.003 & 3.826 & 0.091 & 2.855 & 0.109 & 2.790 & ارتفاع الكرة لحظة الضرب \\
\hline
\end{tabular}

"معنوي عندما تكون قيمة (Sig) (0.05) وعند درجة حرية (11) ومستوى دلالة (0.05) جدول (4) بين الوسط الحسابي والانحراف المعياري وقيمة (t) للاختبار القبلي والبعدي للمجموعة الضابطة للمتغيرات الكينماتيكية لمهارة الضرب الساحق

\begin{tabular}{|c|c|c|c|c|c|c|c|}
\hline \multirow{2}{*}{ الدستوى } & \multirow{2}{*}{ Sig } & \multirow{2}{*}{ قيم المحسوبة } & \multicolumn{2}{|c|}{ الاختبار البعدي } & \multicolumn{2}{|c|}{ الاختبار القبلي } & \multirow{2}{*}{ المتغيرات } \\
\hline & & & $\varepsilon$ & س - س & $\varepsilon$ & س - س & \\
\hline معنوي & 0.001 & 4.293 & 3.449 & 49.583 & 3.725 & 46.666 & زاوية الانطلاق \\
\hline معنوي & 0.000 & 5.121 & 3.761 & 116.833 & 3.333 & 124.250 & اقصى انثاء للركبة \\
\hline معنوي & 0.000 & 7.925 & 0.181 & 4.084 & 0.120 & 3.743 & سرعة الانطلاق \\
\hline معنوي & 0.000 & 5.841 & 0.111 & 2.885 & 0.094 & 2.797 & ارتفاع الكرة لحظة الضرب \\
\hline
\end{tabular}

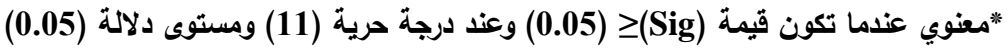
الجدول (5) نتائج اختبار تحليل التباين (F) لأداء مهارة الضرب الساحق وللمتغيرات الكينماتيكية ولمجاميع البحث الثثلاثة

\begin{tabular}{|c|c|c|c|c|c|c|c|}
\hline الدقلالة & الاحصائية & قليمة F المحسوبة & متوسط المربعات & الحرية & المربعات & مصدر التباين & المتغيرات \\
\hline \multirow{2}{*}{ معنوي } & \multirow{2}{*}{0.000} & \multirow{2}{*}{47.524} & 877.750 & 2 & 1755.500 & بين المجموعات & \multirow{2}{*}{ زاوية الانطلاق } \\
\hline & & & 18.470 & 33 & 609.500 & داخل المجموعات & \\
\hline \multirow{2}{*}{ معنوي } & \multirow{2}{*}{0.000} & \multirow{2}{*}{36.327} & 665.528 & 2 & 1331.056 & بين المجموعات & \multirow{2}{*}{ اقصى انثتاء } \\
\hline & & & 18.321 & 33 & 604.583 & داخل المجموعات & \\
\hline \multirow{2}{*}{ معنوي } & \multirow{2}{*}{0.000} & \multirow{2}{*}{42.050} & 3.028 & 2 & 6.058 & بين المجموعات & \multirow{2}{*}{ سرعة انطلاق } \\
\hline & & & 0.072 & 33 & 2.377 & داخل المجموعات & \\
\hline \multirow[b]{2}{*}{ معنوي } & \multirow[b]{2}{*}{0.021} & \multirow[b]{2}{*}{4.378} & 0.047 & 2 & 0.094 & بين المجموعات & \multirow{2}{*}{ للكرة لحظى ارتفاعة الضرب } \\
\hline & & & 0.011 & 33 & 0.354 & داخل المجموعات & \\
\hline
\end{tabular}

يتضح من الجدول رقم (14) ان مستوى الدلالة الإحصائية لمهارة الضرب الساحق أصغر من مستوى الدلالة (0.05) فهذا يدل على وجود فروق معنوية لصالح الاختبارات البعدية لمجاميع البحث الثثلاثة في مهارة الضرب الساحق، لذا فان الذان الفروق

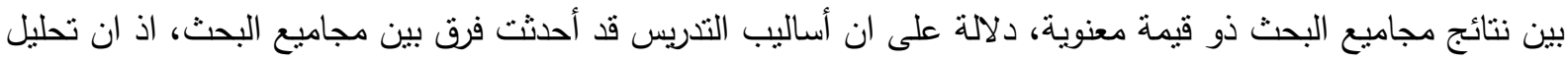

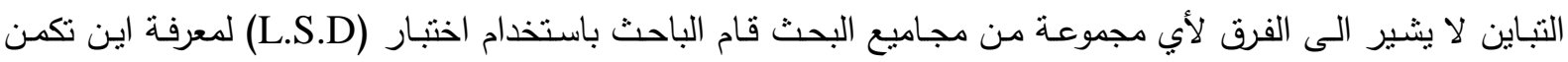
معنوية الفروق. 
الجدول (6) قيمة (L.S.D) للمقارنات البعدية في متغيرات الكينماتيكية للبحث ولمجاميع البحث الثثلاثة في

مهارة الضرب الساحق

\begin{tabular}{|c|c|c|c|c|c|c|}
\hline دلالة الفروق & Sig & فرأ & المجاميع & س & المجموعة & المتغيرات \\
\hline معنوي للاكتشاف & 0.000 & 12.75 & اكتثاف -تعليم & 65.833 & الاكتثناف & \multirow{3}{*}{ زاوية الانطلاق } \\
\hline معنوي للاكتشاف & 0.000 & 16.25 & اكتشاف -ضابطة & 49.583 & 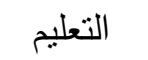 & \\
\hline معنوي للضابطة & 0.054 & 3.5 & التعليم -ضابطة & 53.083 & الضابطة & \\
\hline معنوي للتعليم & 0.000 & 13.583 & اكتشاف -تعليم & 104.750 & الاكتثاف & \multirow{3}{*}{ اقصى انثتاء } \\
\hline معنوي للضابطة & 0.000 & 12.083 & اكتشاف-ضابطة & 118.333 & التعليم & \\
\hline معنوي للتعليم & 0.397 & 1.5 & التعليم -ضابطة & 116.833 & الضابطة & \\
\hline معنوي للاكتشاف & 0.000 & 0.944 & اكتثاف -تعليم & 4.854 & الاكتشاف & \multirow{3}{*}{ سرعة } \\
\hline معنوي للاكتشاف & 0.000 & 0.77 & اكتشاف - ضابطة & 3.910 & التعليم & \\
\hline معنوي للضابطة & 0.121 & 0.174 & التعليم -ضابطة & 4.084 & الضابطة & \\
\hline معنوي للاكتشاف & 0.008 & 0.12 & اكتشاف -تعليم & 2.975 & الاكتشاف & \multirow{3}{*}{ لحظة الضرب الكرة } \\
\hline معنوي للاكتشاف & 0.039 & 0.09 & اكتشاف - ضابطة & 2.855 & التعليم & \\
\hline معنوي للضابطة & 0.495 & 0.03 & التعليم - ضابطة & 2.885 & الضابطة & \\
\hline
\end{tabular}

المناقشة:

يتبن مـن الجدول(6) ان هنـاك فـروق معنويـة في متغيـر زاويـة الانطـلاق بين المجموعـة الأولـى (الاكتثــاف الموجـهـ) والمجموعة الثانية (التعليم المبرمج) ولصالح المجموعة الأولى وبين المجموع الأولى (الاكتثاف الموجه) والمجموعة الثالثة (الضابطة) ولصالح المجموعة الأولى والمجموعة الثانية (التعليم المبرمج) والمجموعة الثالثة ولصالح المجموعة الثالثة، ويعزو الباحث سبب ذلك الى الأسلوب التدريسي المستخدم، اذ كان لاستخدام أسلوب الاكتثاف الموجه دور كبير في تطور

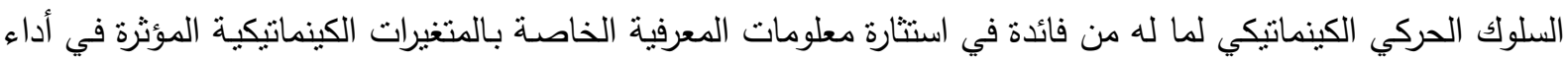
مهارة الضرب الساحق والتي يمنلكها عينة الاكتثاف الموجه ففي متغير زاوية الانطلاق فقد ازدادت الزاوية وبمقدار معنوي اذ ان زيادة زاوية الانطلاق لجسم الطاب تؤدي الى تحقيق ارتفاع عالي للجسم مما يحقق منطلب مهم من متطلبات الأداء

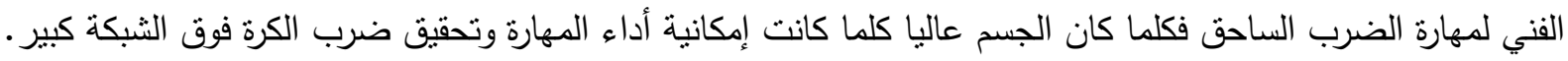
اذا زيادة زوايا الدفع والاقتراب وزاوية الانطلاق والهجوط تعني نقصان من عزم الدوران المقاوم (عزم الوزن) وزيادة عزم القوة

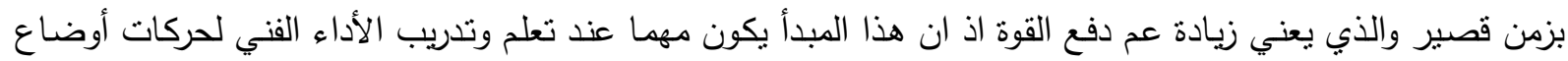

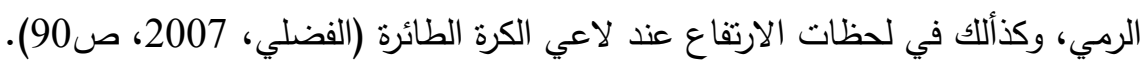
- اما في متغير اقصى انثتاء لركبة فقد ظهرت معنوية الفروق في الاختبار البعدي ولصالح مجموعة الاكتثـاف الموجة وذألك لأنها شهدت نقصان في مقدارها للاختبار البعدي وذألك هدف كينماتيكي مهم في تطوير قدرات الأداء الفني لمهارة

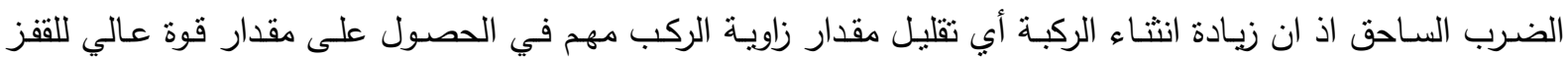

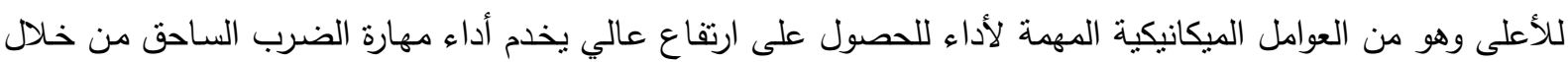

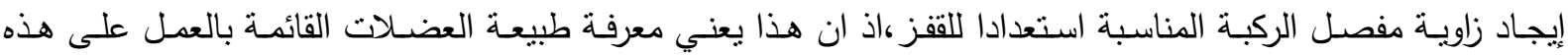
المفاصل من اجل ان تؤمن زاوية العمل في هذه المفاصل اعلى قيم في عزوم القوة ،واقل قيم لعزوم قصور الجسم الذاتية 
كوهذه المفاهيم الميكانيكية تلعب دور أساسي في زيادة المعلومات الخاصـة للمدرس عند نعليم الأقسام التحضيرية لهذه

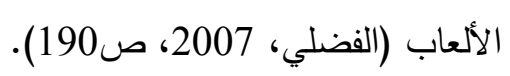

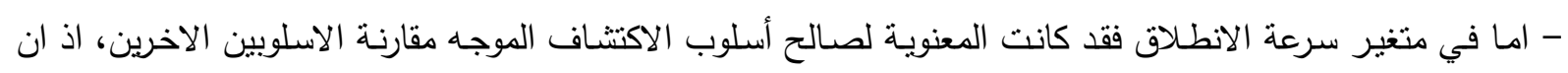
سرعة الانطلاق من المؤشرات الكينماتيكية المهمة لتطوير السلوك الحركي الكينماتيكي وهو مؤشر مهي في تعلم الأداء

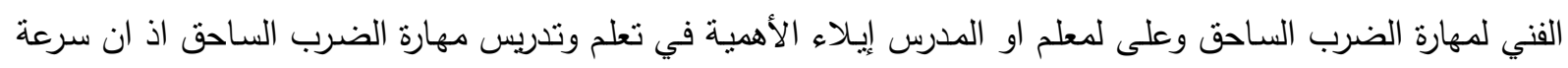
الانطلاق مهم في تحقيق الارتفاع المناسب والمطلوب لأداء المهارة بشكلها النهائي وهو مؤشرة مهم في تعليم الطلبة أداء

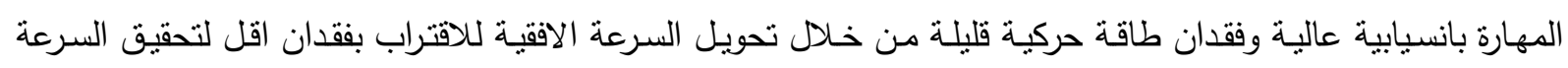

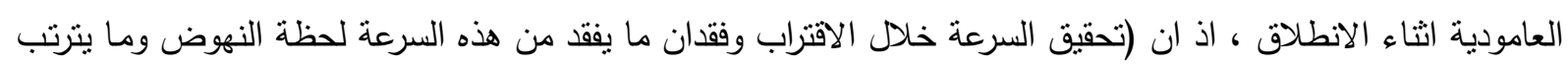

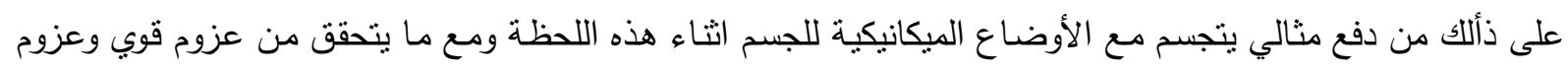

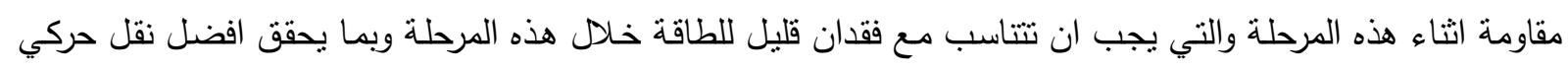

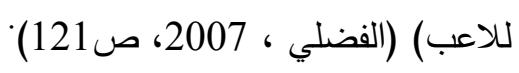

كما ان (إذا كان تغير الزخم بقيمة سالبة قليلة فان ذألك يدل أيضا على انسيابية عالية خصوصا عند لحظات الربط بين

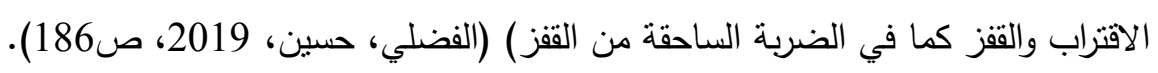

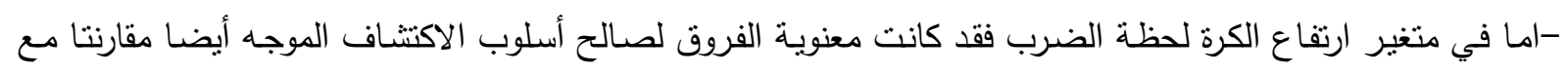
الاسلوبين الاخرين، وهو من المتغيرات المهمة والتي تمثل الناتج قبل النهائي للحركة والمؤثرة بصورة كبير على النئ الناتج النهائي للمهارة المتمثل بضرب الكرة ويمثل متغير ارتفاع الكرة لحظة الضرب نتائج الخطوات التعليمية التي بسـهم بها

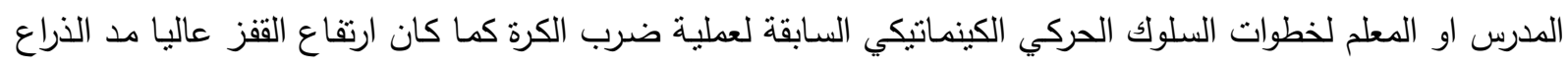

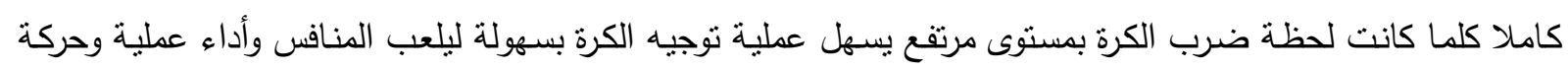

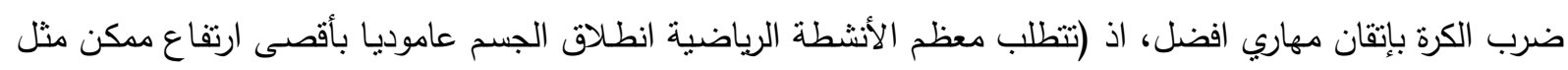

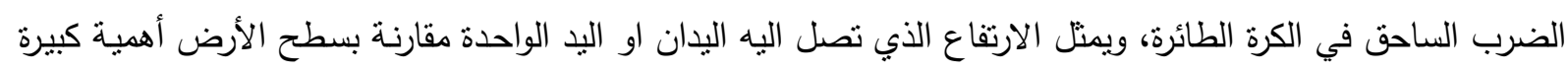

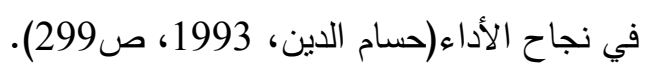

وان هذا المتغير الكينماتيكي يعتمد على المتغيرات الكينماتيكية السابقة الذكر ولها تأثثر كبير على مقدار ارتفاع الكرة لحظة الضرب.

\section{المصادر}

بشائر رحيم الربيعي (2015)؛ أثز التعلم الذاتي وفق الكتيب المبرمج في تعلم ونطور تركيز الانتباه والتصور العقلي وتعلم مهارتي المناولة والتصويب بكرة السلة، بحث منشور في مجلة كربلاء لعلوم التربية الرياضية-جامعة كربلاء، المجلد الثاني، العدد الثالث. ثائر خميس احمد(2011)؛ نأثير أسلوب الاكتشاف الموجه في اكتساب مهارة الارسال بالتسس الأرضي، بحث منشور في مجلة علوم الرياضة -جامعة ديالى، المجلد الثالث، العدد الثالث. حيدر شخي جبار، حسين علي كاظم(2018)؛ البايوميكانيك الرياضي نظريات وتطبيقات، ط1، لعيا، (عمان، دار الوضاح للنشر) . رشاد طارق يوسف(2015)؛ تأثثر أسلوب الاكتشاف الموجه وأسلوب التعلم بالأهداف في تعلم بعض المهارات

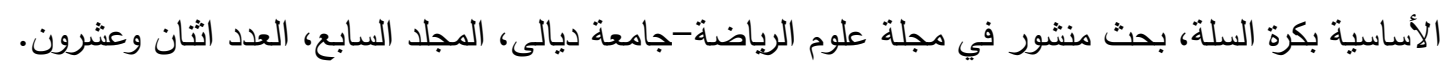


صالح شيروان خضير (2016)؛ تأثير أسلوب الاكتشاف الموجه في تعلم بعض المهارات على جهازي(عارضة التوازن

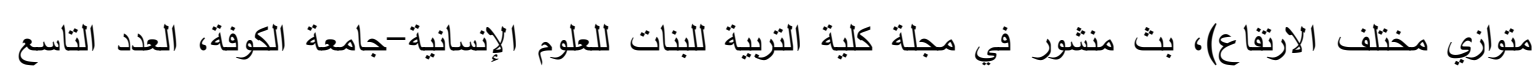
عشر. صريح عبد الكريم الفضلي(2007)؛ تطبيقات البيوميكانيك في التنريب الرياضي والأداء الحركي، (بغداد، مطبعة عدي ، الكعبي). صريح عبد الكريم الفضلي، إيهاب داخل حسين(2019)؛ علم الحركة التطبيقى (الكنسيولوجيا)، ط1، (بغداد مكتبة الفيصل للطباعة والنشر ).

طلحة حسين حسام الدين(1993)؛ الميكانيكا الحيوية الأسس النظرية والنطبيقية، ط1، (القاهرة، دار الفكر العربي). فاتن إسماعيل عادل حميد(2016)؛ تأثير برنامج تعليمي بأسلوب الاكتشاف الموجه في تطوير الانسيابية والنقل

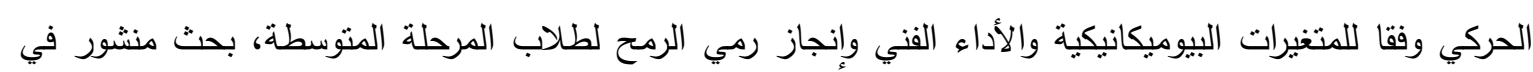
مجلة كلية التربية الأساسية-الجامعة المستتصرية، المجلد الحادي والعشرون، العدد اثثان وتنعون. مجاهد حميد رشيد(2010)؛ الاكتشاف الموجه وتأثثره في مستوى أداء اللعب لمهارة استقبال الارسال بالكرة الطائرة، بحث منشور في مجلة علوم الرياضة-جامعة ديالى، المجلد الثاني، العدد الثاني. مفتي حماد إبراهيم(2000)؛ طرق تدريس العاب الكرات، ط1، (القاهرة، دار الفكر العربي).

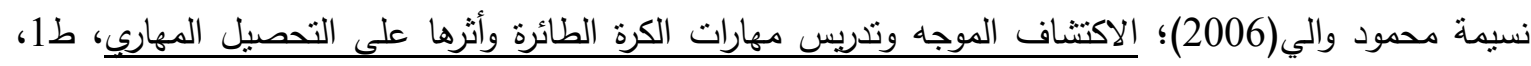
(الإسكندرية، دار الوفاء لدنيا الطباعة والنشر ). نهى عناية الحسيناوي(2008)؛ تأثثر التعلم المبرمج بالنظام الخطي المنسلسل والمتشعب في تعلم مهارتي المحاورة والتمرية الصدرية بكرة السلة، بحث منشورة في مجلة التربية الرياضية-جامعة بغداد، المجلد العشرون، العدد الثاني.

\section{الملاحق}

ملحق (1) ييين اسماء الخبراء الذين نم عليهم عرض استمارة المتغيرات الكينماتيكية لمهارتي الضرب الساحق وحائط الصد

\begin{tabular}{|c|c|c|c|c|}
\hline 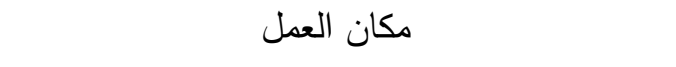 & 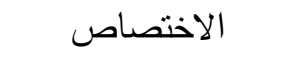 & اللقب العلمي & 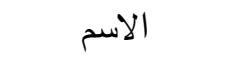 & $ت$ \\
\hline كلية التربية البدنية وعلوم الرياضة /جامعة بغداد & بايوميكانيك جمناستلك & 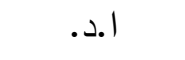 & ياسر نجاح & 1 \\
\hline كلية التربية البدنية وعلوم الرياضة /جامعة ذي قار & بايوميكانيك طائرة & 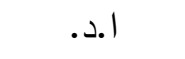 & حيدر شخي & 2 \\
\hline كلية التربية البدنية وعلوم الرياضة /جامعة القادسية & بايوميكانيك طائرة & 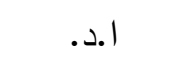 & احمد عبد الامبر & 3 \\
\hline
\end{tabular}


ملحق (2) نموذج لوحدة تعليمية لتعليم مهارة الضرب الساحق بأسلوب الاكتثاف الموجه

$$
\text { الكلية: التربية البدنية وعلوم الرياضة }
$$

الهدف التعليمي: تعليم الطلاب مهارة الضرب الساحق

المرحلة: الثانية

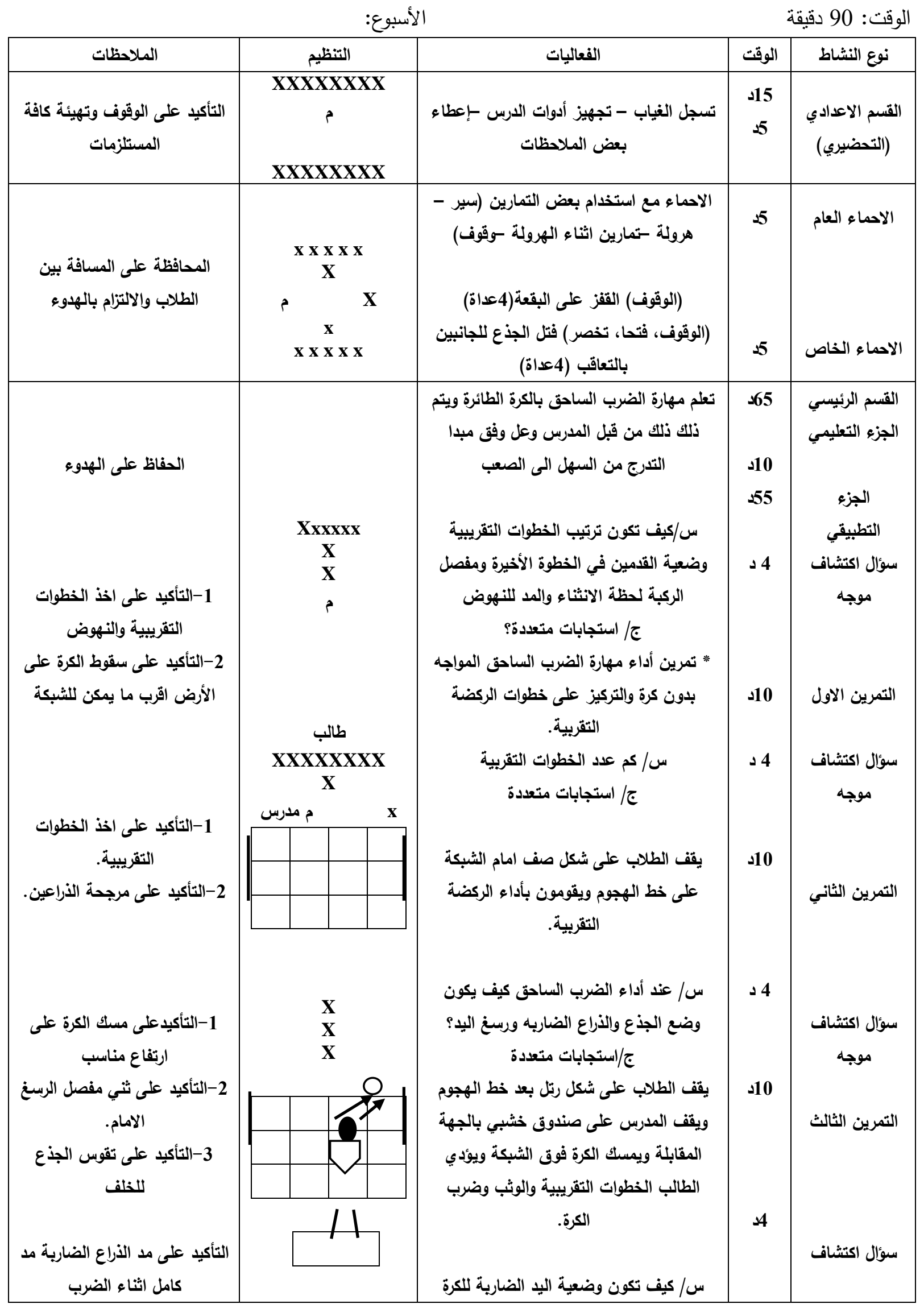


مجلة كلية التربية الرياضية / جامعة بغداد * المجلد الحادي والثلاثون ** العدد الثالث * 2019.

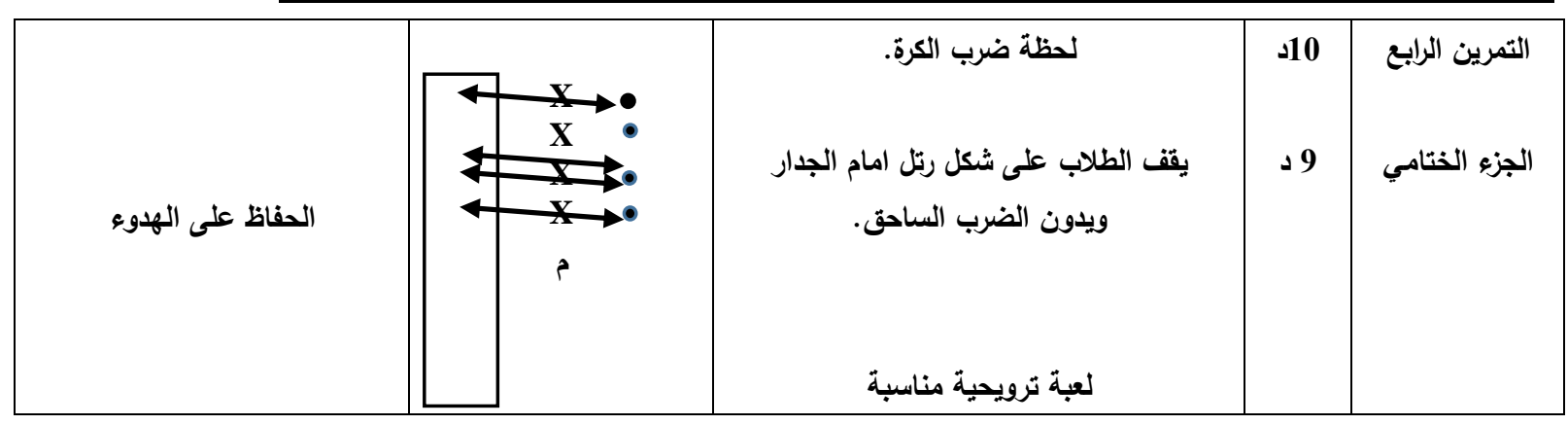

$$
\text { ملحق (3) نموذج لوحدة تعليمية لتعليم مهارة الضرب الساحق بأسلوب التعليم المبرمج }
$$

$$
\text { 12: عدد الطلاب }
$$

الكلية: التربية البدنية وعلوم الرياضة

الهدف التعليمي: تعليم الطلاب مهارة الضرب الساحق.

المرحلة: الثنانية

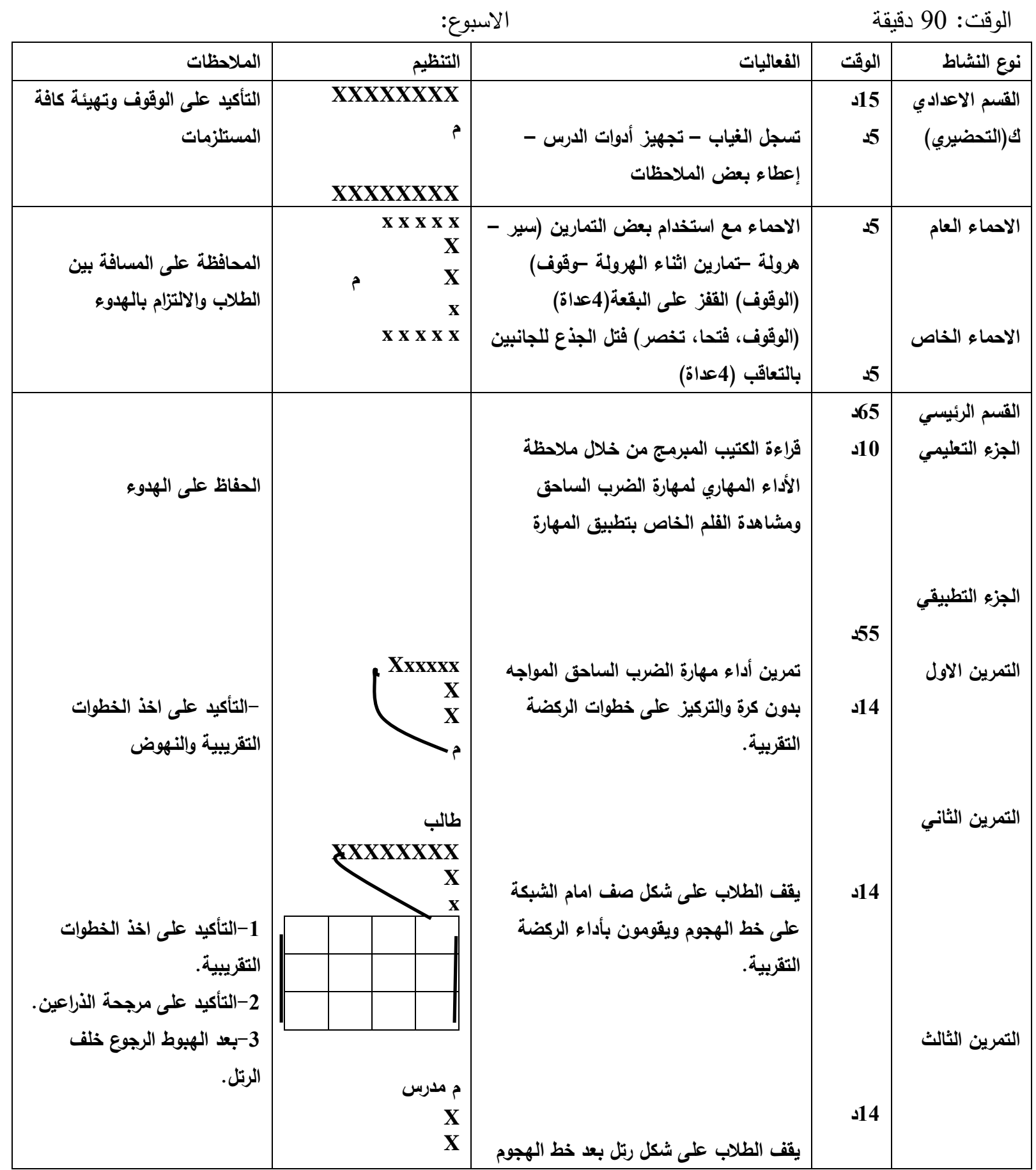


مجلة كلية التربية الرياضية / جامعة بغداد * المجلد الحادي والثلاثون * العدد الثالث * 2019.

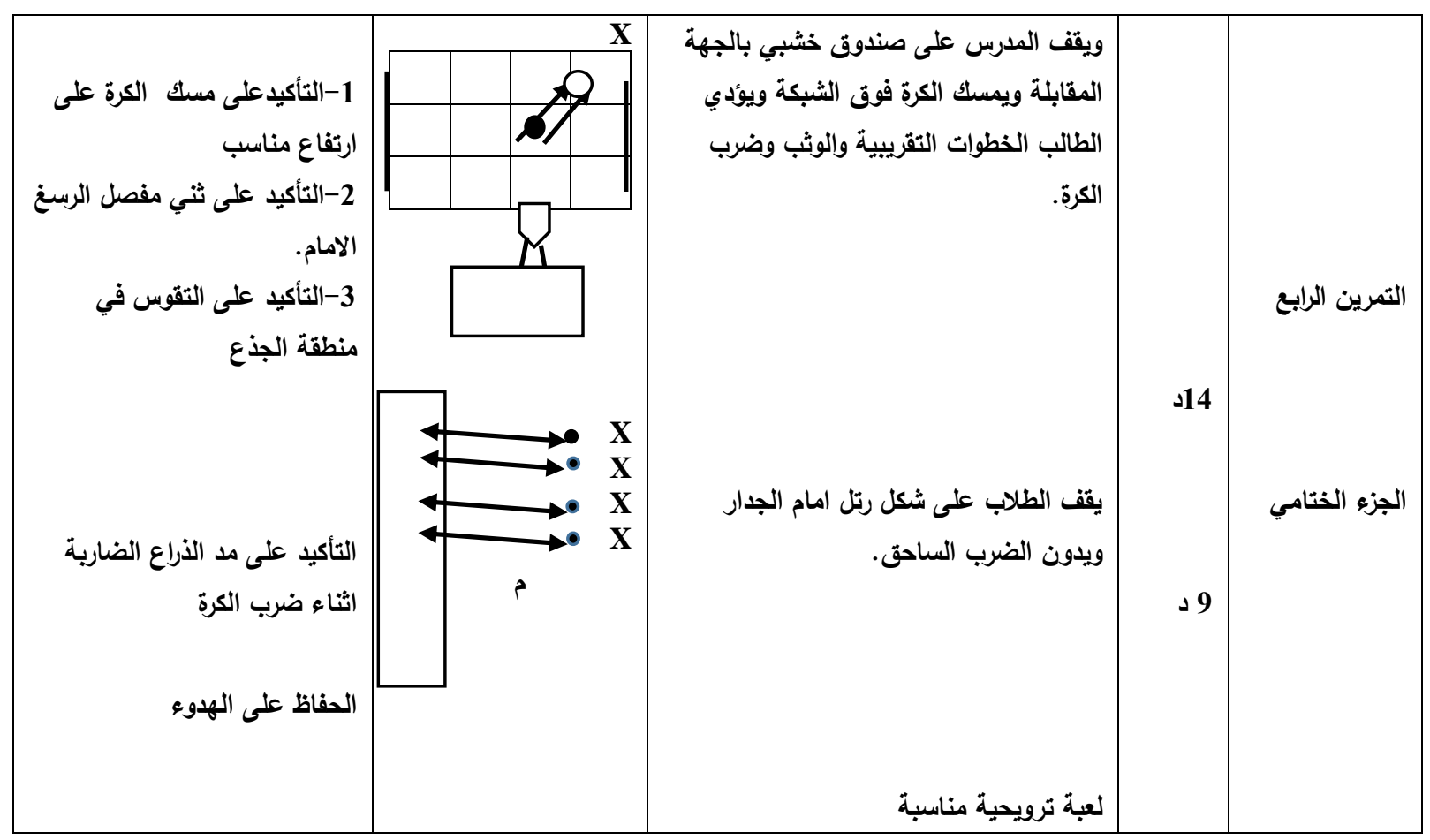

